\title{
Ulcerative colitis disease activity following treatment of associated primary sclerosing cholangitis with cyclosporin
}

\author{
W J Sandborn, R H Wiesner, W J Tremaine, N F Larusso
}

\begin{abstract}
Thirty five adult patients with precirrhotic primary sclerosing cholangitis were randomly allocated to treatment for at least one year with low dose $(4.1 \mathrm{mg} / \mathrm{kg} / \mathrm{day})$ cyclosporin or placebo in a double blind trial. Thirty patients had coexisting ulcerative colitis, including three who had previously undergone colectomy and one who discontinued treatment after three months. Of the remaining 26 patients, 16 received cyclosporin and 10 received placebo. Endoscopy was performed at entry to confirm the diagnosis of inflammatory bowel disease. The ulcerative colitis disease activity was prospectively classified annually as remission/ mild, moderate, or severe using the Truelove and Witt's criteria. Before treatment there were no differences between the cyclosporin and placebo groups in the number of patients with remission/mild colitis, 14/16 (88\%) $v$ 9/10 (90\%), and moderate colitis, $2 / 16(12 \%) v 1 / 10$ $(10 \%)$. During treatment, a remission/mild disease course was present in 15/16 (94\%) $v$ 6/10 (60\%), $p=0.05$ and a moderate disease course in $1 / 16(6 \%) v 4 / 10(40 \%), p=0 \cdot 05$. It is concluded that patients treated with cyclosporin for primary sclerosing cholangitis who have coexisting ulcerative colitis have a more benign course of colitis resulting both from improvement of moderately active colitis and from fewer flares of remission/mildly active colitis. These findings suggest that cyclosporin may be of benefit to the colon in patients with ulcerative colitis who are being treated with cyclosporin for primary sclerosing cholangitis. (Gut 1993; 34: 242-246)
\end{abstract}

Ulcerative colitis and primary sclerosing cholangitis (PSC) are chronic disorders of unknown cause which are presumed to be chronic immune inflammatory in nature. Primary sclerosing cholangitis occurs in $1-6 \%$ of patients with ulcerative colitis ${ }^{1-3}$ and, conversely,

Division of
Gastroenterology and
Internal Medicine, Mayo
Clinic and Mayo
Foundation, Rochester,
Minnesota, USA
W J Sandborn
R H Wiesner
W J Tremaine
N F Larusso
Correspondence to:
Dr R H Wiesner, Mayo Clinic,
200 First St SW, Rochester,
MN 55905, USA.
Accepted for publication
3 August 1992

TABLE I Comparison of patient characteristics at study entry ${ }^{\star}$

\begin{tabular}{lcc}
\hline Variable & $\begin{array}{l}\text { Cyclosporin } \\
(n=16)\end{array}$ & $\begin{array}{l}\text { Placebo } \\
(n=10)\end{array}$ \\
\hline Age (years) & $36(9)$ & $45(10)$ \\
Men (\%) & 63 & 60 \\
Duration of PSC (years) & $2 \cdot 1(4 \cdot 5)$ & $1 \cdot 5(2 \cdot 2)$ \\
Duration of colitis (years) & $8 \cdot 4(8 \cdot 2)$ & $13 \cdot 9(11 \cdot 4)$ \\
Pancolitis (\%) & 94 & 90 \\
Systemic steroids (\%) & 0 & 0 \\
Steroid enemas (\%) & 0 & 10 \\
Sulphasalazine (\%) & 75 & 90 \\
\hline
\end{tabular}

^Indicates no statistically significant differences between cyclosporin and placebo. ulcerative colitis occurs in $56-82 \%$ of patients with primary sclerosing cholangitis. ${ }^{+7}$ It is likely that immunosuppressive treatment of primary sclerosing cholangitis may have some impact on coexisting ulcerative colitis, but this has never been studied.

Cyclosporin is a potent immunosuppressive agent used to prevent allograft rejection in solid organ transplantation. Cyclosporin is also effective treatment in a number of autoimmune diseases, including uveitis, psoriasis, rheumatoid arthritis, myasthenia gravis, chronic active hepatitis, and primary biliary cirrhosis. ${ }^{8-13}$ The mechanism of action is inhibition of $\mathrm{T}$ lymphocyte synthesis of interleukin $2 .{ }^{14}$

Preliminary reports suggest that cyclosporin is effective treatment for Crohn's disease ${ }^{15-20}$ and this has been confirmed in a controlled trial. ${ }^{21}$ Other studies suggest that cyclosporin is of therapeutic value in ulcerative colitis, ${ }^{202-28}$ but there have been no controlled trials. The mechanism of action of cyclosporin in Crohn's disease and ulcerative colitis is not known but may be related to its effects on intestinal cellular immunity. ${ }^{29}$ Cyclosporin has been shown to interfere with the interleukin 2 pathway of immune activation in Crohn's disease..$^{30}$ This study evaluates the disease activity of ulcerative colitis during treatment of coexisting primary sclerosing cholangitis with low dose oral cyclosporin or placebo.

\section{Methods}

\section{PATIENTS}

From 27 June 1985 to 13 July 1988, 35 patients with precirrhotic primary sclerosing cholangitis were randomly allocated to receive low dose cyclosporin (initial dose $5 \mathrm{mg} / \mathrm{kg} /$ day) or placebo in a double blind trial. All patients had histological and cholangiographic findings consistent with primary sclerosing cholangitis, other inclusion and exclusion criteria have been described previously. ${ }^{13}$ Patients were classified according to the severity of their liver disease. ${ }^{13}$ The study was approved by the institutional review board of the Mayo Clinic and all patients gave written consent.

Thirty of the 35 patients $(80 \%)$ had concomitant primary sclerosing cholangitis and ulcerative colitis; 19 received cyclosporin and 11 received placebo. Three of these 30 patients (two in the cyclosporin group and one in the placebo group) were excluded because they had previously undergone colectomy for refractory colitis. In addition, one patient receiving cyclosporin was excluded because treatment was 
TABLE II Ulcerative colitis disease activity

\begin{tabular}{|c|c|c|c|c|}
\hline & \multicolumn{2}{|c|}{$\begin{array}{l}\text { Truelove and Witt's } \\
\text { (remission/ } \\
\text { mild:moderate) }\end{array}$} & \multicolumn{2}{|c|}{$\begin{array}{l}\text { Stool frequency } \\
\text { (stools/day) }\end{array}$} \\
\hline & Before & After ${ }^{\star}$ & Before & After ${ }^{\star}$ \\
\hline $\begin{array}{l}\text { Cyclosporin }(n=16) \\
\text { Placebo }(n=10) \\
\text { p Value }\end{array}$ & $\begin{array}{l}14: 2 \\
9: 1 \\
\text { NS }\end{array}$ & $\begin{array}{l}15: 1 \\
6: 4 \\
0 \cdot 05\end{array}$ & $\begin{array}{l}1 \cdot 9(1 \cdot 2) \\
2 \cdot 0(1 \cdot 0) \\
\text { NS }\end{array}$ & $\begin{array}{l}1 \cdot 6(0 \cdot 3) \\
2 \cdot 7(1 \cdot 5) \\
0.05\end{array}$ \\
\hline \multicolumn{5}{|c|}{$\begin{array}{l}\text { ^Indicates the highest level of disease activity for each patient } \\
\text { during the entire treatment period. } \\
\text { NS Indicates not significant. }\end{array}$} \\
\hline \multicolumn{5}{|l|}{ TABLE III } \\
\hline & & $\begin{array}{l}\text { Cyclosporin } \\
(n=16)\end{array}$ & $\begin{array}{l}\text { Placebo } \\
(n=10)\end{array}$ & p Value \\
\hline $\begin{array}{l}\text { Renal insufficiency } \\
\text { Increased blood presst } \\
\text { Infection } \\
\text { Dysplasia/neoplasia } \\
\text { Headache } \\
\text { Tingling numbness } \\
\text { Tremor } \\
\text { Hirsutism } \\
\text { Gingival hyperplasia } \\
\text { Pancreatitis } \\
\text { Severe nausea/vomitin }\end{array}$ & dret & $\begin{array}{l}1 \\
2 \\
3 \\
0 \\
5 \\
4 \\
2 \\
2 \\
1 \\
0 \\
1\end{array}$ & $\begin{array}{l}0 \\
1 \\
1 \\
2 \\
0 \\
0 \\
0 \\
0 \\
0 \\
1 \\
0\end{array}$ & $\begin{array}{l}\text { NS } \\
\text { NS } \\
\text { NS } \\
\text { NS } \\
0 \cdot 07 \\
\text { NS } \\
\text { NS } \\
\text { NS } \\
\text { NS } \\
\text { NS } \\
\text { NS }\end{array}$ \\
\hline \multicolumn{5}{|c|}{$\begin{array}{l}\text { ^Renal insufficiency defined as a serum creatinine }>141 \mu \mathrm{mol} / \mathrm{l} \text { or } \\
\text { a reduction in the iothalamate clearance below } 70 \mathrm{ml} / \mathrm{min} \text {. } \\
\dagger \text { Increased blood pressure defined as an increase of } \geq 25 \mathrm{~mm} \mathrm{Hg} \text { in } \\
\text { systolic pressure or } \geq 12 \mathrm{~mm} \mathrm{Hg} \text { in diastolic pressure. This does } \\
\text { not include two patients in the placebo group with pre-existing } \\
\text { hypertension. } \\
\text { NS indicates not significant. }\end{array}$} \\
\hline
\end{tabular}

discontinued after only three months. The remaining 26 patients form the cohort for this study. The diagnosis of ulcerative colitis was based on chronic diarrhoea, an endoscopic appearance consistent with colitis, and colon histology consistent with chronic colitis. There were no differences between the cyclosporin and placebo groups in patient characteristics (Table I) or ulcerative colitis disease activity (Table II) at study entry.

\section{TREATMENT}

All 26 patients completed at least one year of treatment, including 16 patients receiving cyclosporin and 10 patients receiving placebo. The duration of treatment (mean (SD)) was $2 \cdot 8(1 \cdot 4)$ years in the cyclosporin group and $3.0(1 \cdot 4)$ years in the placebo group. Treatment was discontinued when patients developed evidence of cirrhosis or portal hypertension. Whole blood cyclosporin trough levels were measured weekly for two months and then monthly for the remainder of the study using high performance liquid chromatography. ${ }^{31}$ Intramural physician monitors adjusted the cyclosporin doses to maintain cyclosporin trough levels between 80 and $120 \mathrm{ng} / \mathrm{ml}$ thus allowing the investigators to remain blinded to the study treatment. The mean maintenance dose in patients receiving cyclosporin was (mean (SD)) $4 \cdot 1(1 \cdot 1) \mathrm{mg} / \mathrm{kg} /$ day taken orally in two equal doses and the mean cyclosporin trough level was $90(25) \mathrm{ng} / \mathrm{ml}$. This low dose of cyclosporin was chosen to minimise toxicity since prolonged treatment (up to five years) was planned.

\section{ULCERATIVE COLITIS DISEASE ACTIVITY}

Patients were evaluated at entry, after the first six months, and then annually. At each visit the temperature, pulse, haemoglobin, and erythrocyte sedimentation rate were measured. In addition, patients were questioned about their bowel habits (stool frequency and stool blood) during the time since their last evaluation and responses were recorded based on the most severe symptoms that the patient had experienced. The patients' clinical disease activity during the interval period was then classified as remission/mild, moderate, or severe using Truelove and Witt's ${ }^{32}$ criteria. We used these criteria rather than a disease activity index which incorporates both clinical symptoms (stool frequency, faecal blood, overall wellbeing) and endoscopic findings ${ }^{33}$ because the patients were not readily available for endoscopy between the yearly evaluations. Truelove and Witt's criteria were originally developed to classify acute disease attacks and therefore do not include a category for remission. Without endoscopy, it is not possible to differentiate between remission and mildly active disease (one to four non-bloody stools/day without accompanying systemic illness). We therefore used the remission/mild disease category to include both patients in remission and patients with mildly active disease. Differentiation between remission/mild and moderate disease is mostly a function of stool frequency. To evaluate this parameter independently the mean stool frequency was calculated for each group at entry and during the study.

All patients underwent colonoscopy or flexible sigmoidoscopy before study entry to confirm the diagnosis of ulcerative colitis. The reports from these endoscopies were reviewed and the endoscopic disease severity was classified as normal, mild, moderate, or severe using Baron's ${ }^{34}$ mucosal appearance criteria. Follow up endoscopy was performed in many patients but this was not done systematically.

\section{TOXICITY}

A physical examination was performed at entry, after six months, and then annually for at least one year. The examiner specifically looked for complications known to be related to cyclosporin, including tingling and numbness in the extremities, tremor, headache, hirsutism, gingival hyperplasia, and infection. If present, these complications were dealt with individually.

Renal function was followed by measuring the serum creatinine at entry, weekly for one month, and then monthly for the remainder of the study. An iothalamate clearance study ${ }^{35}$ was performed at entry and then annually. If the serum creatinine rose above $141 \mu \mathrm{mol} / 1$ then the dose was reduced by one third and the serum creatinine was measured again in several days. If the trough cyclosporin level was in the therapeutic range $(80-120 \mathrm{ng} / \mathrm{ml})$ and the rise in serum creatinine did not correct after reducing the dose, then treatment was discontinued until the serum creatinine returned to pretreatment values.

After instruction, blood pressure was measured and recorded by the patient daily for one month and then three times/week for the remainder of the study. These measurements were returned to the investigators. Persistent hypertension was treated by standard methods 
and if it did not resolve then the dose of the study drug was reduced.

\section{STATISTICAL ANALYSIS}

Parametric (Student's $t$ test) and non-parametric (Fisher's exact test) methods were used where appropriate to compare the cyclosporin and placebo groups before and after treatment. A two tailed $\mathrm{p}$ value below 0.05 was considered significant.

\section{Results}

\section{CLINICAL DISEASE ACTIVITY}

At entry, remission/mild colitis was present in 14 of 16 patients in the cyclosporin group and nine of 10 in the placebo group. Of these patients, 13 in the cyclosporin group and six in the placebo group continued to have remission/mild disease throughout the study. Colitis flares of moderate severity occurred during the study in one patient receiving cyclosporin (two flares) and in three patients receiving placebo (one flare/patient).

Two of 16 patients in the cyclosporin group and one of 10 patients in the placebo group had moderately active colitis at entry into the study. Both patients receiving cyclosporin had a reduction in disease severity from moderate to remission/mild. The patient receiving placebo continued to have moderately active disease. This patient had a previous left hemi-colectomy with a transverse colon rectal anastomosis for a colonic stricture. We elected to include this patient in the study since the entire remaining right colon had active ulcerative colitis.

Overall, out of 16 patients in the cyclosporin group, 15 had a remission/mild disease course are for differences betwee are for differences between th groups. NS indicates not significant.
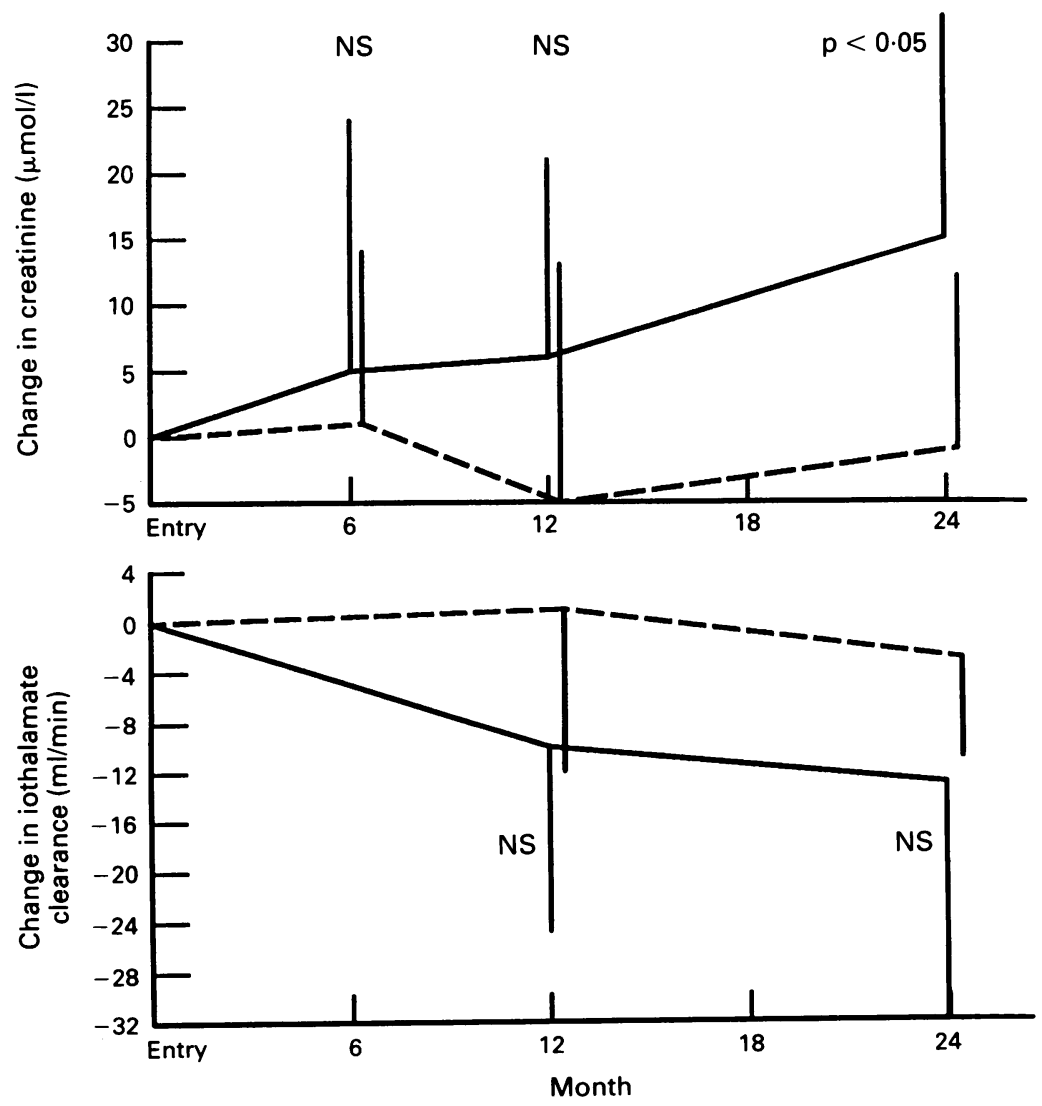

and one had a moderate disease course during treatment (Table II). In comparison, out of 10 patients in the placebo group, six had a remission/mild disease course and four had a moderate disease course during the study. The differences in disease severity during the study were paralleled by a higher mean stool frequency for the placebo group as compared with the cyclosporin group, $2.7 v 1.6$ stools/day (Table II). None of the patients in either group had severe colitis at entry or developed a severe flare during the study. Classification of the disease course (remission/mild, moderate or severe) and calculation of the mean stool frequency were both based on the highest level of disease activity experienced during the entire study. Patients receiving sulphasalazine at study entry (cyclosporin group $75 \%$, placebo group $90 \%$ ) continued to take the drug throughout the study and did not reduce the dose. All the patients who experienced disease flares were taking sulphasalazine. The sulphasalazine dose was increased in some of these patients but this increase always occurred after the flare started when the colitis had already been classified as moderately active. No patients required corticosteroid treatment for colitis flares.

\section{ENDOSCOPIC DISEASE ACTIVITY}

At entry, quiescent or mildly active colitis was seen at endoscopy in 15 of 16 patients in the cyclosporin group and nine of 10 in the placebo group. Follow up endoscopy was performed in many patients but this was not done systematically. Cyclosporin treated patients had 22 follow up endoscopies: 10 at one year; six at two years; four at three years; and two at four years. Placebo treated patients had 12 follow up endoscopies: eight at one year; and four at two years. The overall concordance between the clinical and endoscopic level of severity was 93\% (cyclosporin group $97 \%$, placebo group $86 \%$ ). Because endoscopic follow up was inconsistent, we did not attempt to make an assessment of endoscopic disease activity during the treatment period.

\section{TOXICITY}

Side effects occurred in both the cyclosporin and placebo groups but were more common in patients receiving cyclosporin (Table III). Nephrotoxicity (defined in the study protocol as a serum creatinine $>141 \mu \mathrm{mol} / \mathrm{l}$ or a reduction in the iothalamate clearance below $70 \mathrm{ml} / \mathrm{min}$ ) occurred only in the cyclosporin treated group. One patient $(6 \%)$ had a rise in serum creatinine to $203 \mu \mathrm{mol} / \mathrm{l}$ and none of the patients had an iothalamate clearance less than $70 \mathrm{ml} / \mathrm{min}$. There was a rise in the mean serum creatinine which reached statistical significance after two years and a trend towards a decline in the mean iothalamate clearance in cyclosporin treated patients (Fig 1). In most cases, however, the magnitude of these changes was not sufficient to qualify as nephrotoxicity.

Hypertension, which was easily controlled with anti-hypertensive treatment, occurred in two patients treated with cyclosporin and one patient treated with placebo. There were no 
significant differences in the mean systolic or diastolic blood pressures at one and two years when compared with entry for either the cyclosporin or placebo groups. Infections appeared to occur more commonly in the cyclosporin group, although the difference was not statistically significant. Recurrent oral and vaginal yeast infections occurred in two patients receiving cyclosporin and oral thrush occurred in one patient receiving placebo. All three patients responded to temporary withdrawal of the study drug and topical nystatin treatment. One patient receiving cyclosporin developed bacterial cholangitis. Cyclosporin treatment was stopped but the patient continued to deteriorate and died from sepsis and shock in spite of antibiotic treatment.

None of the patients who received cyclosporin developed dysplasia or tumours. In the placebo group one patient underwent colectomy after high grade dysplasia of the colon was found at colonoscopy and another patient developed a cholangiocarcinoma, which resulted in death. Other side effects which occurred only in the cyclosporin group included headaches, tingling and numbness in the extremities, tremor, hirsutism, and gingival hyperplasia. When these cyclosporin specific side effects occurred, there may have been a tendency for the study drug to be disclosed. The number of patients with side effects was small, however (Table III), and several different investigators evaluated patients. ${ }^{36}$ These factors probably minimised unblinding. One patient receiving cyclosporin had severe nausea and vomiting and had to discontinue the study after one year. Pancreatitis occurred in one patient receiving placebo.

\section{Discussion}

Up to the present all patients treated with cyclosporin for ulcerative colitis have had severe, refractory disease and there are no published controlled trials. Several case reports have suggested that oral cyclosporin is effective in inducing clinical and endoscopic remission. ${ }^{2022-24}$ Two larger series have shown conflicting results. Lichtiger $^{25}$ reported that 11 of 15 patients with severe ulcerative colitis responded to a short course of intravenous (IV) cyclosporin $(4 \mathrm{mg} / \mathrm{kg}$ / day) followed by oral cyclosporin $(6-8 \mathrm{mg} / \mathrm{kg} /$ day) for six months, and that nine of the 11 responders remained in remission during the follow up period. In contrast, Bianchi Porro ${ }^{26}$ reported five patients treated with oral cyclosporin $(8.5 \mathrm{mg} / \mathrm{kg} / \mathrm{day})$ and five patients treated with IV cyclosporin ( $4 \mathrm{mg} / \mathrm{kg} /$ day) followed by oral azathioprine in the responders. All five patients receiving oral cyclosporin had a remission but relapse occurred within three months of discontinuing the drug. Three of the five patients treated with IV cyclosporin had a remission and one of these three had a relapse nine months later while receiving azathioprine. There are two pilot studies suggesting that cyclosporin enemas are effective for proctosigmoiditis. ${ }^{27} 28$

Ulcerative colitis associated with primary sclerosing cholangitis is usually quiescent or only mildly active but a few patients do have moderately active disease. Our results show that patients treated with low dose cyclosporin for primary sclerosing cholangitis are more likely to have a disease course characterised by remission or mild activity than are patients receiving placebo. These results are the first controlled data to suggest that cyclosporin may be of clinical benefit in patients with ulcerative colitis. These findings are surprising since it is more difficult to show efficacy when the majority of patients have remission/mild disease. A clinical trial specifically designed to assess the efficacy of cyclosporin treatment for patients with mildly or moderately active ulcerative colitis would be of interest. Such a trial would be unethical, however, given the unfavourable risk/benefit ratio of cyclosporin treatment in this setting. In spite of the methodological problems discussed below, this study design is probably the only ethical way to obtain placebo controlled data on the efficacy of cyclosporin in patients with mildly and moderately active ulcerative colitis.

The validity of comparing the effects of cyclosporin and placebo on ulcerative colitis in patients who were not randomly admitted to the study or removed from the study on the basis of ulcerative colitis disease activity can be justified as follows. Firstly, although patients were randomly admitted to the study on the basis of severity of liver disease, patients with ulcerative colitis in the placebo and cyclosporin treated groups had similar characteristics, including mean age, sex ratio, mean duration of colitis, extent of colitis, concomitant therapy, and ulcerative colitis disease severity (Tables I-II). Secondly, the mean duration of treatment before study termination was similar in both groups. This is not surprising since the groups were balanced at study entry for severity of liver disease and cyclosporin was not effective in altering the natural progression of primary sclerosing cholangitis to cirrhosis. ${ }^{36}$ Our results compare the disease activity at entry with the most severe disease activity experienced during the entire treatment period for each patient. To confirm that differences in treatment duration for individual patients did not affect the analysis, we also compared ulcerative colitis disease activity in the placebo and cyclosporin groups at one year when all patients were still in the study. The ultimate clinical course of the colitis became evident during the first year of the study and there was no difference between the one year analysis and the final analysis (Table II) performed after a mean follow up of $2 \cdot 8$ years in the placebo group and 3.0 years in the cyclosporin group.

Concern about nephrotoxicity has been the major factor limiting more widespread investigational use of cyclosporin in ulcerative colitis. Most patients without renal disease receiving cyclosporin have a $20 \%$ or more decline in renal function during the first six months of treatment with little progression thereafter. ${ }^{37}$ These changes are usually reversible within two weeks of stopping the drug. In the two largest studies using cyclosporin for inflammatory bowel disease the incidence of nephrotoxicity was $7-10 \% .{ }^{21}{ }^{25}$ In all instances the toxicity was easily reversed by reducing the cyclosporin dose. Patients receiving cyclosporin in our study had a $20 \%$ rise in mean serum creatinine and a $14 \%$ 
reduction in mean iothalamate clearance at two years. Only one patient $(6 \%)$ receiving cyclosporin met our criteria for nephrotoxicity and that patient improved after reducing the dose. These findings suggest that low doses of cyclosporin can be given for prolonged periods to patients with ulcerative colitis with minimal nephrotoxicity.

The incidence of minor infections including thrush and candida vaginitis was slightly higher in patients receiving cyclosporin but the difference was not statistically significant. These infections cleared up after standard treatment and temporary discontinuation of the cyclosporin. One patient died from cholangitis and sepsis. Since cholangitis is a frequent complication of primary sclerosing cholangitis, it is not clear that cyclosporin contributed to this death.

A further concern about treating ulcerative colitis with cyclosporin is the carcinogenic risk in patients who already have an increased incidence of colonic dysplasia and carcinoma. In addition, there is a small risk of developing lymphoma with cyclosporin immunosuppression. Most of the reported cases had associated Epstein-Barr viral infection and occurred during treatment with high doses of cyclosporin in combination with corticosteroids and azathioprine. ${ }^{38}{ }^{39}$ Our results showed no increase in the incidence of any malignancies in patients receiving cyclosporin, although the mean follow up is only $2 \cdot 8$ years.

In conclusion, patients treated with cyclosporin for primary sclerosing cholangitis who have coexisting ulcerative colitis have a more benign course of colitis resulting both from improvement of moderately active colitis and fewer flares in patients with remission/mild colitis. Significant cyclosporin toxicity during prolonged treatment is minimal and does not appear to be a limiting factor at this dose of cyclosporin. Further controlled trials are needed to define clearly the role of cyclosporin in the treatment of ulcerative colitis.

Supported by grants from the Sandoz Corporation and the Mayo Foundation

Presented at the annual meeting of the American College of Gastroenterology, 12-16 October 1991, Boston.

1 Schrump E, Fausa O, Kolmannskog F, Elgjo G, Ritland S, Gjone E. Sclerosing cholangitis in ulcerative colitis. A follow-up study. Scand F Gastroenterol 1982; 17: 33-9.

2 Rasmussen HH, Fallingborg J, Mortensen PB, Freund L, Rasmussen SN. Primary sclerosing cholangitis in patients
with ulcerative colitis during a 12-year period. Scand $\mathcal{F}$ Gastroenterol 1989; 24 (suppl 159): 57

3 Olsson R, Danielsson A, Jarnerot G, Lindstrom E, Loof L, Rolny $\mathbf{P}$, et al. Prevalence of primary sclerosing cholangitis in patients with ulcerative colitis. Gastroenterology 1991; 100: in patients

4 Wiesner RH, LaRusso NF. Clinicopathological features of the syndrome of primary sclerosing cholangitis. Gastroenterology 1980; 79: 200-6.

5 Chapman RWG, Marborgh BA, Rhodes JM, Summerfield JA, Dick R, Scheuer PJ, et al. Primary sclerosing cholangitis: a review of its clinical features, cholangiography, and hepatic histology. Gut 1980; 21 : 870-7.

6 Helzberg JH, Peterson JM, Boyer JL. Improved survival with primary sclerosing cholangitis. A review of clinicopathologic features and a comparison of symptomatic and asymptomatic patients. Gastroenterology 1987; 92: 1869-75.

7 Aadland E, Schrumpf E, Fausa O, Elgjo K, Heilo A, Aakhus $\mathrm{T}$, et al. Primary sclerosing cholangitis: a long-term followup study. Scand 7 Gastroenterol 1987; 22: 655-64.

8 Nusenblatt RB, Palestine AG, Chan CC. Cyclosporin A therapy in the treatment of intraocular inflammatory disease resistant to systemic corticosteroids and cytotoxic agents. Am 7 Ophthalmol 1983; 96: 275-82.

9 Ellis CN, Gorsulowsky DC, Hamilton TA, Billings JK, Brown $\mathrm{MD}$, Headington JT, et al. Cyclosporine improves psoriasis in a double-blind study. FAMA 1986; 256: 3110-6.

10 Dougados M, Awada H, Amor B. Cyclosporin in rheumatoid arthritis: a double-blind, placebo-controlled study in 52 patients. Ann Rheum Dis 1988; 47: 127-33.

11 Tindall RSA, Rollins JA, Phillips JT, Greenlee RG, Wells L, Belendiuk G. Preliminary results of a double-blind, randomized, placebo-controlled trial of cyclosporine in myasthenia gravis. N Engl F Med 1987; 316: 719-24.

12 Hyams JS, Ballow M, Leichtner AM. Cyclosporine treatment of auto-immune chronic active hepatitis. Gastroenterology 1987; 93: 890-3.

13 Wiesner RH, Ludwig J, Lindor KD, Jorgensen RA, Baldus WP, Homberger HA, et al. A controlled trial of cyclosporine WP, Homberger HA, et al. A controlled trial of cyclosporine in the treatment of

14 Hess AD, Tutschka PJ, Santos GW. Effect of cyclosporin A on human lymphocyte response in vitro. III. CsA inhibits the production of $T$ lymphocyte growth factors in secondary mixed lymphocyte responses but does not inhibit the response of primed lymphocytes to TCGF. F Immunol 1982; 128: $355-9$.

15 Allison MC, Pounder RE. Cyclosporin for Crohn's disease. Aliment Pharmacol Therap 1987; 1: 39-43.

16 Peltekian KM, Williams CN, MacDonald AS, Roy PD, Czolpinska E. Open trial of cyclosporine in patients with severe Crohn's disease refractory to conventional therapy. Can 7 Gastroenterol 1988; 2: 5-11.

17 Parrot NR, Taylor RMR, Venables CW, Record CO. Treatment of Crohn's disease in relapse with cyclosporin A. ment of Crohn's disease in
Brf Surg 1988; 75: 1185-8.

18 Fukushima T, Sugita A, Masuzawa S, Yamazaki Y, Tsuchiya S. Effects of cyclosporin A on active Crohn's disease. Gastroenterol f pn 1989; 24: 12-5.

19 Brynskov J, Binder V, Riis P, Lauritsen K, Schaffalitzky De Muckadell O, Freund L, et al. Low-dose cyclosporin for Crohn's disease; implications for clinical trials. Aliment Pharmacol Therap 1989; 3: 135-42.

20 Stange EF, Fleig WE, Rehklau E, Ditschuneit H. Cyclosporin A treatment in inflammatory bowel disease. Dig Dis $S c i$ A treatment in inf 138 : 1387-92.

21 Brynskov J, Freund L, Rasmussen SN, Lauritsen K, Schaffalitzky De Muckadell O, Williams N, et al. A placeboSchaffalitzky De Muckadell O, Williams N, et al. A placebocontrolled, double-blind, randomized trial of cyclosporine therapy

22 Gupta S, Keshavarzian A, Hodgson HJF. Cyclosporin in ulcerative colitis. Lancet 1984; ii: 1277-8.

23 Shelly ED, Shelly WB. Cyclosporine therapy for pyoderma gangrenosum associated with sclerosing cholangitis and ulcerative colitis. F Am Acad Dermatol 1988; 18: 1084-8.

24 Hyams JS, Treem WR. Cyclosporine treatment of fulminant colitis. F Pediatr Gastroenterol Nutr 1989; 9: 383-7.

25 Lichtiger S, Present DH. Preliminary report: cyclosporin in treatment of severe active ulcerative colitis. Lancet 1990 336: 16-9.

26 Bianchi Porro G, Petrillo M, Ardizzone S. Cyclosporine treatment for severe active ulcerative colitis. Lancet 1990 ; 336: 439 .

27 Brynskov J, Freund L, Thomsen OO, Anderson CB, Rasmussen SN, Binder V. Treatment of refractory ulcerative colitis with cyclosporine enemas. Lancet 1989; i: 721-2.

28 Ranzi T, Campanini MC, Velio P, Quarto Di Palo F, Bianch PA. Treatment of chronic proctosigmoiditis with cyclosporin enemas. Lancet 1989; ii: 97.

29 MacDermott RP. Cell-mediated immunity in gastrointestina disease. Hum Pathol 1986; 17: 219-33.

30 Brynskov J, Tvede N. Plasma interleukin-2 and a soluble/shed interleukin-2 receptor in serum of patients with Crohn's disease. Effect of cyclosporine. Gut 1990; 31: 795-9.

31 Sawchuk AJ, Cartier LL. Liquid chromatographic determination of cyclosporine A in blood and plasma. Clin Chem 1981; 27: 1368-71.

32 Truelove SC. Treatment of ulcerative colitis with local hemisuccinate sodium: a report on a controlled therapeutic trial. BMF 1958; ii: 1072-7.

33 Schroeder KW, Tremaine WJ, Ilstrup DM. Coated oral 5 -aminosalicylic acid therapy for mildly to moderately active ulcerative colitis: a randomized study. $N$ Engl f Med 1987 317: 1625-9.

34 Baron JH, Connell AM, Lennard-Jones JE. Variation between observers in describing mucosal appearances in proctocolitis. BMF 1964; i: 89-92.

35 Sigman EM, Elwood CM, Knox F. The measurement of glomerular filtration rate in man with sodium iothalamate glomerular filtration rate in man with

36 Wiesner RH, Steiner B, LaRusso NF, Lindor KD, Baldus Wiesner RH, Steiner $\mathrm{B}$, 'LaRusso $\mathrm{NF}$, Lindor $\mathrm{KD}$, Baldus
WP. A controlled clinical trial evaluating cyclosporine in the WP. A controlled clinical trial evaluating cyclosporine in the treatment of prin $14: 63 \mathrm{~A}$.

37 Tegzess AM, Doorenbos BM, Minderhound JM, Donker AJM. Prospective serial renal function studies in patients with nonrenal disease treated with
Transplant Proc 1988; 20 (suppl 2): 390-3.

38 Palestine AG, Nussenblatt RB, Chan CC. Side effects of systemic cyclosporine in patients not undergoing transplantation. Am $\mathcal{F}$ Med 1984; 77: 652-6.

39 Cockburn I. Assessment of risks of malignancy and lymphomas developing in patients using Sandimmune. Transplant Proc 1987; 19: 1804-7. 